Marquette University

e-Publications@Marquette

School of Dentistry Faculty Research and

Publications

Dentistry, School of

9-1-2017

\title{
Evaluation of Die Trim Morphology Made by CAD-CAM Technology
}

Pratiksha Agrawal

Marquette University

Geoffrey A. Thompson

Marquette University, geoffrey.thompson@marquette.edu

Seok-Hwan Cho

Marquette University, seokhwan.cho@marquette.edu

Gerald J.Ziebert

Marquette University

Accepted version. The Journal of Prosthetic Dentistry, Vol. 118, No. 3 (September 2017): 406-412. DOI. (C) 2017 Elsevier B.V. Used with permission. 
Marquette University

e-Publications@Marquette

\section{Dentistry Faculty Research and Publications/School of Dentistry}

This paper is NOT THE PUBLISHED VERSION; but the author's final, peer-reviewed manuscript. The published version may be accessed by following the link in the citation below.

The Journal of Prosthetic Dentistry, Vol. 118, No. 3 (September, 2017): 406-412. DOI. This article is (C) Elsevier and permission has been granted for this version to appear in e-Publications@Marquette. Elsevier does not grant permission for this article to be further copied/distributed or hosted elsewhere without the express permission from Elsevier.

\section{Contents}

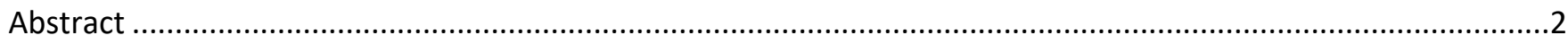

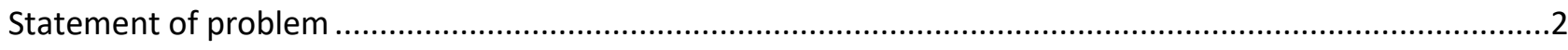

Purpose

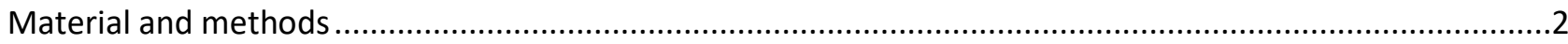

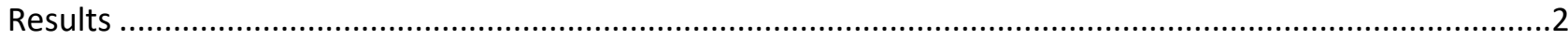

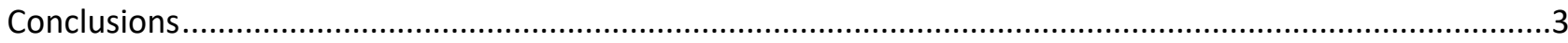

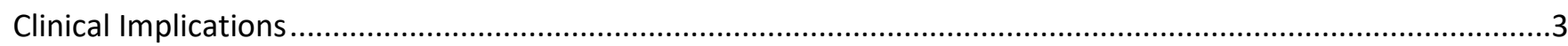

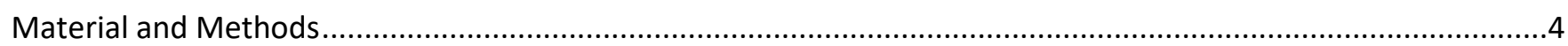

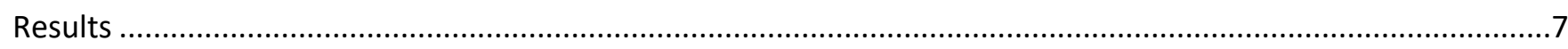

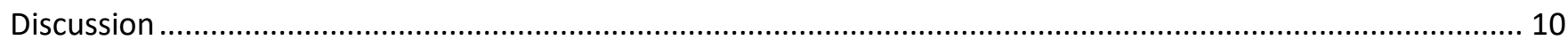

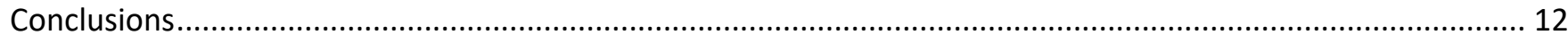

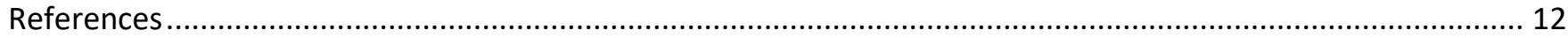

\section{Evaluation of Die Trim Morphology Made by CAD-CAM Technology}




\section{Pratiksha Agrawal}

Graduate Prosthodontics, Marquette University School of Dentistry, Milwaukee, WI

\section{Geoffrey Thompson}

Postgraduate Program in Prosthodontics, Marquette University School of Dentistry, Milwaukee, WI

\section{Seok-Hwan Cho}

Department of General Dental Sciences, Marquette University School of Dentistry, Milwaukee, WI

\section{Gerald J. Ziebert}

Postgraduate Program in Prosthodontics, Marquette University School of Dentistry, Milwaukee, WI

\section{Abstract}

Statement of problem

The die contour can affect the emergence profile of prosthetic restorations. However, little information is available regarding the congruency between a stereolithographic (SLA) die and its corresponding natural tooth.

\section{Purpose}

The purpose of this vitro study was to evaluate the shapes of SLA die in comparison with the subgingival contour of a prepared tooth to be restored with a ceramic crown.

\section{Material and methods}

Twenty extracted human teeth, 10 incisors, and 10 molars, were disinfected and mounted in a typodont model. The teeth were prepared for a ceramic restoration. Definitive impressions were made using an intraoral scanner from which 20 SLA casts with removable dies were fabricated. The removable dies and corresponding human teeth were digitized using a 3-dimensional desktop scanner and evaluated with computer-aided design software. The subgingival morphology with regard to angle, length, and volume at the buccolingual and mesiodistal surfaces and at zones $A, B, C$, and D were compared. Data were first analyzed with repeated measures analysis of variance (ANOVA), using locations (buccolingual and mesiodistal), zones (A, B, C, and D), and model type (SLA and Natural) as within-subject factors and tooth type (molar and incisor) as the between-subject factor. Post hoc analyses were performed to investigate the difference between natural teeth and corresponding SLA models, depending upon the interaction effect from the repeated measures ANOVA $(\alpha=.05)$.

\section{Results}

For angle analysis, the incisor group demonstrated a significant difference between the natural tooth and SLA die on the buccolingual surfaces $(P<.05)$, whereas the molar group demonstrated a significant difference at the mesiodistal surfaces $(P<.05)$. For the evaluation of length and volume, the incisor 
group showed significant differences in zone $D$ on both the buccolingual $(P<.05)$ and the mesiodistal $(P<.05)$ surfaces. However, significant differences in zones $C(P<.05)$ and $\mathrm{D}(P<.05)$ on the buccolingual surfaces and in all zones on the mesiodistal surfaces were observed in the molar group.

\section{Conclusions}

For the comparison of angles, SLA dies did not replicate the subgingival contour of natural teeth on the buccolingual surfaces of the incisal groups. For the comparison of length and volume, SLA dies were more concave and did not replicate the subgingival contour of natural teeth in the incisal and molar groups.

\section{Clinical Implications}

The shape of SLA-manufactured dies may negatively affect the emergence profile of definitive dental restorations.

The direct oral fabrication of patterns for extracoronal and intracoronal restorations is possible; however, the procedure is inconvenient for the patient, difficult to accomplish well, requires additional time at the chair, and is nearly impossible to do in some situations. Therefore, cast-die systems were developed to overcome the challenges of direct pattern fabrication. A cast-die system is necessary to replicate the clinical situation so that this information can be used in the laboratory. ${ }^{1} \mathrm{~A}$ die is a working replica of a single tooth or several teeth. $\frac{1}{-}$ Traditionally, a cast-die system has been used to produce fixed dental prostheses in the laboratory. $\underline{\underline{2}}$

After an intraoral impression is made and cast in stone, dies must be trimmed to remove unnecessary information before fabricating a cast restoration. The trimmed region is usually soft tissue but may be a reproduction of the displacement cord, blood, or saliva. Trimming unnecessary material will help visualize the finish line on the die. Die trimming areas are divided into 3 zones: margin, body, and base. $\underline{-}$ The marginal zone is the area which extends from the finish line to 3 to $5 \mathrm{~mm}$ apically. This zone is the most critical die trimming area, as it determines the emergence profile and contour of a restoration made on the die. The body is the connection between the marginal zone and the base. The base is the most apical extent of the die and determines the stopping point of the die when placed on the cast. $\underline{3}, \underline{4}$

Accurate die fabrication is important because an excessively trimmed marginal zone may produce a large and overcontoured restoration. However, an undertrimmed marginal zone will produce a restoration with a flat and straight contour. Therefore, die trimming must attempt to reproduce the subgingival contour of the teeth being restored in order to achieve an appropriate emergence profile. The term "emergence profile" was first used in 1977 by Stein and Kuwata 5 to describe tooth and crown contours as the contours traversed the soft tissue. Later, it was defined by Croll $\underline{5}$ as the portion of the axial tooth contour extending from the base of the gingival sulcus past the free gingival margin and into the oral environment. Croll 5 stated that the emergence profile is the most crucial link between tooth form and gingival health, preventing plaque-retentive areas and facilitating the maintenance of oral hygiene. The clinical longevity of prostheses may be directly related to proper coronal contours. $\underline{6}, \underline{7}$, 
8, 9 An overcontoured restoration may lead to food and bacterial plaque accumulation along the margins and consequently to inflammation and caries. Moreover, many studies have found that overcontoured restorations are more detrimental to the surrounding tissue than an undercontoured or flat crown. $\underline{10}, \underline{11}, \underline{12}, \underline{13}, \underline{14}$ Perel $\underline{11}$ conducted a study in dogs and found that overcontouring produced inflammation, whereas undercontouring did not. Parkinson 15 found an increase in the faciolingual dimension in the definitive restorations and found that the plaque index was significantly higher for both complete coverage metal-ceramic restorations and complete metal crowns compared with control teeth. It was also noted that the greater the axial prominences on complete crown restorations, the greater the quantity of plaque. $\underline{15}$ Therefore, consideration should be given to developing a normal contour on prosthetic restorations.

Currently, computer-aided design and computer-aided manufacturing (CAD-CAM) can fabricate a stereolithographic (SLA) definitive cast with dies. Many studies have focused on the comparison between conventional and CAD-CAM cast dimensional accuracy. Guth et al $\underline{16}$ conducted an in vitro study to determine the accuracy of digital casts obtained by direct and indirect data capture. Datasets were generated using the $3 \mathrm{M}$ Lava COS digitized polyether impressions and by scanning the reference gypsum cast using the Lava Scan ST laboratory scanner. Direct digitization using 3M Lava COS showed statistically significantly higher accuracy than with the impression-making and indirect digitization. $\underline{16}$ Nedelcu and Persson 17 conducted an in vitro study comparing the scanning accuracy and precision of 4 intraoral scanners, the 3M Lava COS, the Cerec AC/Bluecam, the E4D, and the iTero. Casts were fabricated in 3 materials (poly[methyl methacrylate]; Telio CAD; titanium, and zirconia), and the reference cast was scanned using an industrial optical scanner. Data were evaluated with 3dimensional (3D) analysis and software, and significant differences were found between coating and noncoating scanners. In another in vitro study, Cho et al $\underline{18}$ compared the accuracy and reproducibility of digitally generated casts made using the $3 \mathrm{M}$ Lava scanner with those of a conventional stone cast. Results showed that the digital casts were less accurate and less reproducible than the conventional casts in terms of the entire cast area. Finally, Patzelt et al $\underline{19}$ found differences in the dimensional accuracy and precision of definitive casts produced by different intraoral scanners systems. Milled casts were less accurate than SLA printed casts. Although SLA technology was found to be superior, all casts possessed a clinically acceptable level of accuracy.

However, to the authors' knowledge, no studies have assessed the accuracy of digital dies. The purpose of this study was to evaluate the subgingival contour of SLA dies produced from extracted human teeth prepared to receive a complete ceramic restoration. The research hypothesis was that no difference would be found between the reference tooth and the SLA die.

\section{Material and Methods}

The institutional review board determined that the study did not require oversight (letter on file). Twenty extracted human teeth were cleared of adherent material by scrubbing with detergent and water, followed by immersion in $5.25 \%$ sodium hypochlorite solution for 10 minutes. The teeth were mounted on an endodontic dentoform (ModuPro Endo; Acadental) with polyvinyl siloxane putty (Aquasil EasyMix Putty Smart Wetting impression material; Dentsply Sirona). $\stackrel{14}{ }$ The coronal one-third of 
the root was covered with autopolymerizing denture rebase material (Reliance DuraBase Hard Chairside Reline; Reliance Dental Mfg Co), which simulated the gingiva. The typodont model simulated a patient, and complete ceramic crown preparations were made on each tooth. Two groups were included for study, an incisor group with 10 maxillary incisors and a molar group with 10 molars.

Tooth preparations were made with a total convergence angle of between 10 and 20 degrees, an incisal or occlusal reduction of $2 \mathrm{~mm}$, a uniform axial reduction of $1.5 \mathrm{~mm}$, and a deep chamfer facial finish line and a lingual chamfer. All finish lines were placed $1 \mathrm{~mm}$ supragingivally. Crown preparations were completed by a single experienced practitioner (P.A.). Twenty digital impressions were made using an intraoral scanner (Lava Chairside Oral Scanner; 3M ESPE) (COS). After the digital impressions were captured, data were transferred to the $3 \mathrm{M}$ laboratory center for fabrication of 20 SLA casts with dies.

After cast fabrication, the natural teeth were removed from the typodont model and SLA dies from the SLA casts (Fig. 1). The prepared tooth and its corresponding digital die were digitized using a 3D desktop scanner (D8100; 3 shape) to create standard tessellation language (STL) files (Fig. 2). Each prepared tooth and the SLA die were compared using CAD software (Rhino 5; McNeel North America). Comparisons were made of the subgingival morphology in 2 locations, the buccolingual (BL) and mesiodistal (MD) surfaces and in zones $A, B, C$, and $D$. Zone $A$ was an area between the lowest point on the finish line and $0.5 \mathrm{~mm}$ apical to that line; zone $B$ was 0.5 to $1 \mathrm{~mm}$ apical to the finish line; zone $C$ was from 1 to $1.5 \mathrm{~mm}$ apical to the finish line; and zone $D$ was 1.5 to $2 \mathrm{~mm}$ apical to the finish line (Fig. 3). Three different parameters, angle, length, and volume, were measured and compared among the teeth and their corresponding SLA die. The first parameter, angle, was measured using screen ruler software (the triangular screen ruler 5.3; MB-Ruler; Markus-Brader). A line beginning at the highest point on the margin and parallel to the long axis of the tooth was drawn, and angles were measured on the surface of the tooth and SLA die at a point $1 \mathrm{~mm}$ below the margin and on 4 different surfaces: buccal (B), lingual (L), mesial (M), and distal (D) (Fig. 4). A positive value indicated the surface was convex, and a negative value meant the surface had a concave profile. The second parameter, length, was measured in zones, $A, B, C$, and $D$. The upper and the lower surfaces of each zone were measured for each zone (Fig. 3 C). The last parameter, volume, was also measured in zones $A, B, C$, and D by sectioning the zones in the $\mathrm{BL}$ and $\mathrm{MD}$ areas (Fig. 3D). Means \pm standard deviations (SD) were determined for each measurement.

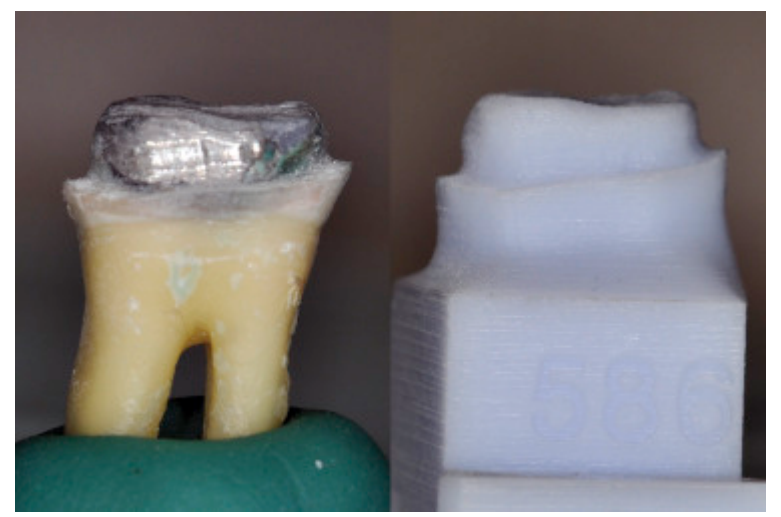


Figure 1. Prepared molar (left) and corresponding stereolithography die (right).

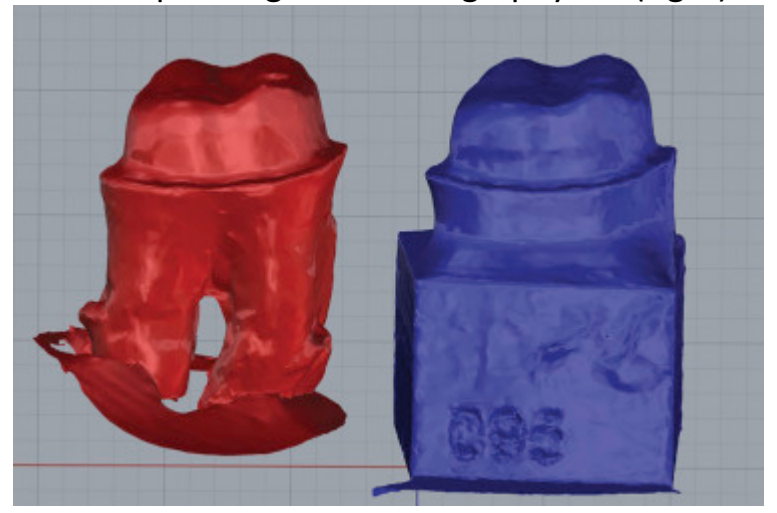

Figure 2. Standard tessellation language file image of prepared molar (red) and corresponding stereolithography die (blue).
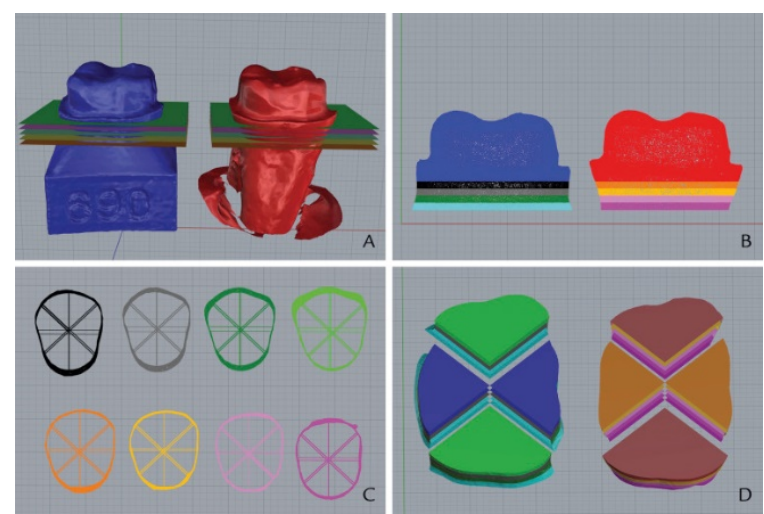

Figure 3. A, Sectioning process of prepared molar (red) and corresponding stereolithography cast die (blue). B, Sectioned view of 4 zones by $0.5-\mathrm{mm}$ increments. C, Diagram indicating length measurement for buccolingual and mesiodistal distance for prepared molar (bottom) and corresponding stereolithography dies (top). D, Diagram indicates volume measurement for buccolingual and mesiodistal areas for prepared molar (right) and corresponding stereolithography dies (left).

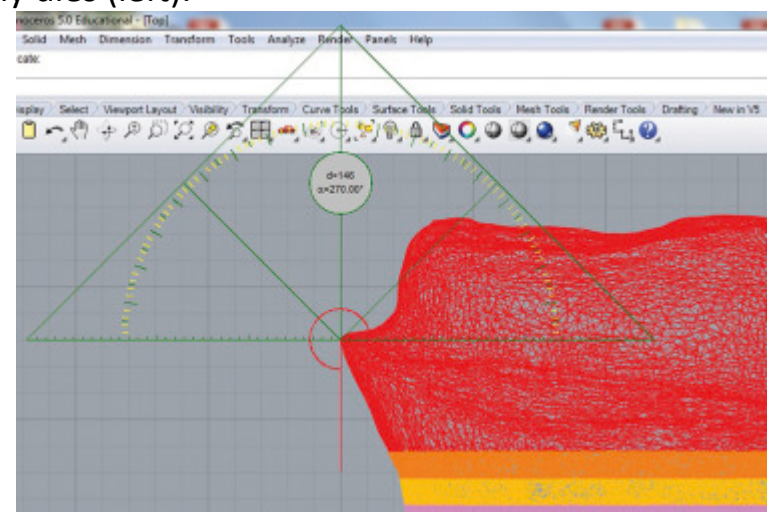

Figure 4. Screen capture showing angle measurement procedure with triangular screen ruler.

Statistical analyses were performed using repeated measures analysis of variance. For distance and volume data, location ( $B L$ and $M D)$, zones ( $A, B, C$, and $D)$, and model-type (SLA and natural) were considered within-subject factors and tooth type (molar and incisor) as the between-subject factor. For 
angle data, location and model were considered within-subject factors and tooth type as the betweensubject factor. Furthermore, post hoc analyses were performed to determine the differences between natural teeth and corresponding SLA models depending upon the interaction effect from the repeated measures ANOVA (IBM SPSS Statistics V23; IBM Corp). Departure from normal distributions was evaluated by using Q-Q plots. To address multiplicity of hypotheses testing with familywise error rate control, the $P$ values were adjusted by Bonferroni correction ( $\alpha=.05)$. For the angle data, a significant interaction $(P<.05)$ was found between model type and location. Consequently, post hoc analyses were performed to compare the angle data of SLA and natural teeth for each location. For distance and volume data, a significant interaction $(P<.05)$ was also found between the model type (SLA and natural teeth) and zone and location. Consequently, post hoc analyses were performed to compare SLA and natural teeth for each location and each zone.

\section{Results}

Table 1 summarizes the angle analysis between teeth and SLA dies on 4 surfaces for both incisors and molars. In the incisor group, a statistically significant difference was found on the BL surfaces $(P<.05)$, whereas the molar group demonstrated a statistically significant difference on the MD surfaces $(P<.05)$.

Table 1. Comparison of mean $\pm S D$ angle of teeth and SLA dies on BL and MD surfaces by post hoc test $(\alpha=.05)$

\begin{tabular}{lllll} 
Surface and Location & \multicolumn{2}{l}{ Incisors } & \multicolumn{3}{l}{ Molars } \\
\cline { 2 - 5 } & Mean (degree) & \pm SD & Mean (degree) & \pm SD \\
\hline BL & & & & \\
Teeth (B) & -3.3 & 8.39 & -10.9 & 9.86 \\
SLA (B) & 7.8 & 3.36 & -9.7 & 5.71 \\
Teeth (L) & $-3.2^{\mathrm{b}}$ & 13.87 & -11.5 & 8.99 \\
SLA (L) & $-21.4^{\mathrm{b}}$ & 5.38 & -10.1 & 6.09 \\
MD & & & & \\
Teeth (M) & -4.5 & 7.25 & $-11.5^{\mathrm{c}}$ & 8.20 \\
SLA (M) & -3.9 & 3.60 & $-3.5^{\mathrm{C}}$ & 2.42 \\
Teeth (D) & -11.3 & 8.07 & $-15.1^{\mathrm{d}}$ & 5.19 \\
SLA (D) & -7.4 & 3.83 & $-8.2^{\mathrm{d}}$ & 5.34
\end{tabular}

B, buccal; D, distal; L, lingual; M, mesial; BL, buccolingual; MD, mesiodistal; SLA, stereolithography.

Same superscript letters in column indicates statistical difference.

Table 2 shows the length comparisons. A statistically significant difference was observed in the incisor group between natural teeth and SLA dies in zone $D$ on both the BL and the MD surfaces $(P<.05)$. The 
molar group displayed statistically significant differences in zones $C$ and $D$ on the $B L$ surface and in zones $A, B, C$, and $D$ on the MD surface $(P<.05)$

Table 2. Comparison of mean $\pm S D$ length of teeth and SLA dies $(\mathrm{mm})$ on BL and MD surfaces by post hoc test $(\alpha=.05)$

\begin{tabular}{|c|c|c|c|c|}
\hline \multirow[t]{2}{*}{ Surface and Zone } & \multicolumn{2}{|l|}{ Incisors } & \multicolumn{2}{|l|}{ Molars } \\
\hline & Mean $(\mathrm{mm})$ & $\pm \mathrm{SD}$ & Mean $(\mathrm{mm})$ & $\pm \mathrm{SD}$ \\
\hline \multicolumn{5}{|l|}{ BL } \\
\hline \multicolumn{5}{|l|}{ A } \\
\hline Teeth & 6.33 & 0.83 & 10.08 & 1.77 \\
\hline SLA & 6.38 & 0.86 & 10.19 & 1.47 \\
\hline \multicolumn{5}{|l|}{ B } \\
\hline Teeth & 6.26 & 0.73 & 9.76 & 1.86 \\
\hline SLA & 6.24 & 0.84 & 9.96 & 1.50 \\
\hline \multicolumn{5}{|l|}{ C } \\
\hline Teeth & 6.19 & 0.60 & $9.42^{\circ}$ & 1.98 \\
\hline SLA & 6.21 & 0.87 & $9.99^{\circ}$ & 1.43 \\
\hline \multicolumn{5}{|l|}{ D } \\
\hline Teeth & 6.10 & 0.48 & $9.14^{d}$ & 2.12 \\
\hline SLA & 6.43 & 0.77 & $10.28^{d}$ & 1.40 \\
\hline \multicolumn{5}{|l|}{ MD } \\
\hline \multicolumn{5}{|l|}{ A } \\
\hline Teeth & 5.30 & 0.76 & $8.87^{\mathrm{e}}$ & 0.96 \\
\hline SLA & 5.36 & 0.82 & $9.49^{e}$ & 1.11 \\
\hline \multicolumn{5}{|l|}{ B } \\
\hline Teeth & 5.22 & 0.77 & $8.65^{f}$ & 0.95 \\
\hline SLA & 5.34 & 0.83 & $9.47^{f}$ & 1.13 \\
\hline \multicolumn{5}{|l|}{ C } \\
\hline Teeth & 5.16 & 0.78 & $8.37^{8}$ & 0.86 \\
\hline SLA & 5.41 & 0.87 & $9.58^{9}$ & 1.21 \\
\hline \multicolumn{5}{|l|}{ D } \\
\hline Teeth & $5.11^{\mathrm{b}}$ & 0.77 & $8.17^{\mathrm{h}}$ & 0.83 \\
\hline SLA & $5.58^{\mathrm{b}}$ & 0.89 & $9.81^{\mathrm{h}}$ & 1.27 \\
\hline
\end{tabular}

BL, buccolingual; MD, mesiodistal; SLA, stereolithography. 
Same superscripted letters in column indicates statistical difference.

The volume comparisons between teeth and SLA dies are shown in Table 3. Not unexpectedly, the results were the same as the length analysis. For the incisor group, a statistically significant difference was observed in zone $\mathrm{D}$ on both the $\mathrm{BL}(P<.05)$ and the $\mathrm{MD}(P<.05)$ surfaces, whereas for the molar group, statistically significant differences were found between zones $C$ and $D$ on the $B L$ surface and among all zones on the MD surface $(P<.05)$.

Table 3. Comparison of mean \pm SD volume between teeth and SLA dies $\left(\mathrm{mm}^{3}\right)$ on $B L$ and MD surfaces by post hoc test $(\alpha=.05)$

\begin{tabular}{|c|c|c|c|c|}
\hline \multirow[t]{2}{*}{ Surface and Zone } & \multicolumn{2}{|l|}{ Incisors } & \multicolumn{2}{|l|}{ Molars } \\
\hline & Mean $\left(\mathrm{mm}^{3}\right)$ & $\pm \mathrm{SD}$ & Mean $\left(\mathrm{mm}^{3}\right)$ & $\pm S D$ \\
\hline \multicolumn{5}{|l|}{ BL } \\
\hline \multicolumn{5}{|l|}{ A } \\
\hline Teeth & 7.50 & 1.91 & 21.43 & 7.10 \\
\hline SLA & 7.72 & 2.10 & 21.88 & 6.30 \\
\hline \multicolumn{5}{|l|}{ B } \\
\hline Teeth & 7.54 & 1.69 & 20.74 & 6.63 \\
\hline SLA & 7.60 & 1.89 & 21.30 & 6.09 \\
\hline \multicolumn{5}{|l|}{ c } \\
\hline Teeth & 7.14 & 1.62 & $19.78^{\circ}$ & 6.37 \\
\hline SLA & 7.60 & 1.88 & $21.26^{\circ}$ & 6.04 \\
\hline \multicolumn{5}{|l|}{ D } \\
\hline Teeth & 7.10 & 1.13 & $18.73^{\mathrm{d}}$ & 6.46 \\
\hline SLA & 8.28 & 1.93 & $22.76^{d}$ & 5.89 \\
\hline \multicolumn{5}{|l|}{ MD } \\
\hline \multicolumn{5}{|l|}{ A } \\
\hline Teeth & 5.64 & 1.14 & $17.67 \mathrm{e}$ & 3.72 \\
\hline SLA & 6.38 & 1.82 & $19.85^{\mathrm{e}}$ & 4.96 \\
\hline \multicolumn{5}{|l|}{ B } \\
\hline Teeth & 5.64 & 1.22 & $16.82^{f}$ & 3.32 \\
\hline SLA & 6.32 & 1.81 & $19.29^{t}$ & 4.20 \\
\hline \multicolumn{5}{|l|}{ c } \\
\hline Teeth & 5.50 & 1.29 & $15.90^{\circ}$ & 3.00 \\
\hline SLA & 6.48 & 1.91 & $19.70^{\circ}$ & 4.36 \\
\hline \multicolumn{5}{|l|}{ D } \\
\hline Teeth & $5.44^{\mathrm{b}}$ & 1.28 & $15.02^{h}$ & 2.72 \\
\hline SLA & $7.00^{\mathrm{b}}$ & 2.09 & $21.02^{h}$ & 4.77 \\
\hline
\end{tabular}


A-D, zones. BL, buccolingual; MD, mesiodistal; SLA, stereolithography.

Same superscript letters in column indicates statistical difference.

\section{Discussion}

The shape of SLA dies made by CAD-CAM technology was investigated. Three different parameters, angle, length, and volume, were compared. The null hypothesis was rejected as a statistically significant difference $(P<.05)$ was found between SLA-fabricated dies and their corresponding natural teeth for both the incisor and the molar groups.

With respect to angle and incisor group, the magnitude of the facial surface angle for the SLA dies was positive ( 7.8 degrees), whereas the natural teeth were on average negative ( -3.3 degrees). In addition, the lingual surfaces of SLA dies demonstrated large negative angles (-21.4 degrees) compared with those of natural teeth ( -3.2 degree). This difference in the incisor group could be attributed to the labial angulation of the maxillary anterior teeth in the maxillary arch. Andrews $\underline{20}$ discussed the 6 keys for normal occlusion, the keys being molar relationships, crown angulation, crown inclination, rotations, tight contacts, and occlusal plane. He stated that the maxillary central and lateral incisors have a natural labiolingual inclination, which might explain the difference noted between the prepared teeth and the SLA dies. Figure 5 demonstrates the differences in contour of the buccal and lingual surfaces because natural teeth tend to incline; the lingual surface of the SLA dies (Fig. 5 , blue) possesses a more concave (negative value of angle) shape than the buccal surface (positive value of angle). Although the maxillary anterior teeth have a certain labial inclination, the SLA dies were trimmed perpendicular to their die base. This could produce an angular difference on the buccal and lingual surfaces compared with the corresponding natural tooth's subgingival morphology. However, molars have a different pattern of angulation determined by the curves of Spee and Wilson. .0 Because of the Spee and Wilson curves, mandibular molars tend to tilt in a mesial direction. Only the MD surfaces of molars in the present study demonstrated a significant difference, which can, in part, be explained by the Spee curve.

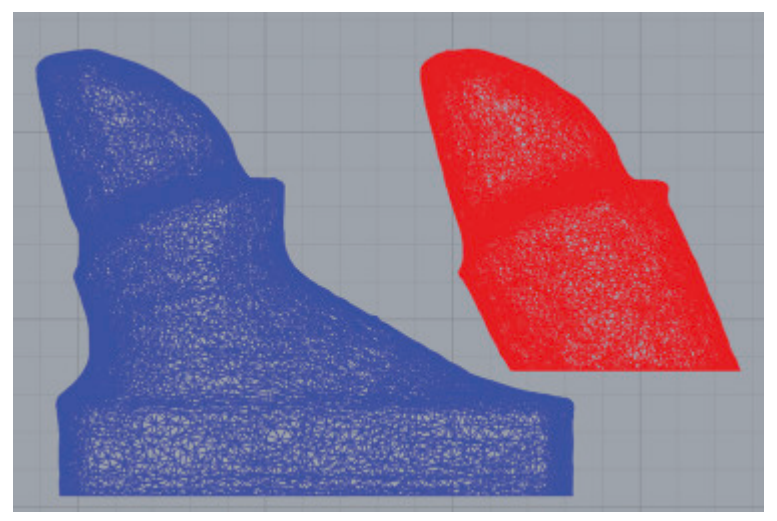

Figure 5. Screen capture of profiles demonstrate differences between natural tooth inclination and stereolithography dies. 
With regard to length for incisors, Figure 6 shows a graph of the differences between the other zones and zone $A$. The graph indicates that prepared teeth gradually became narrower, whereas SLA dies became wider and more concave in zone D. However, for the length of molars, the SLA dies were wider than the prepared tooth. Figure 6 shows a graph of the differences in length between the other zones and that of zone A for molars. The prepared teeth became narrower while the SLA dies became wider and showed a concave shape.
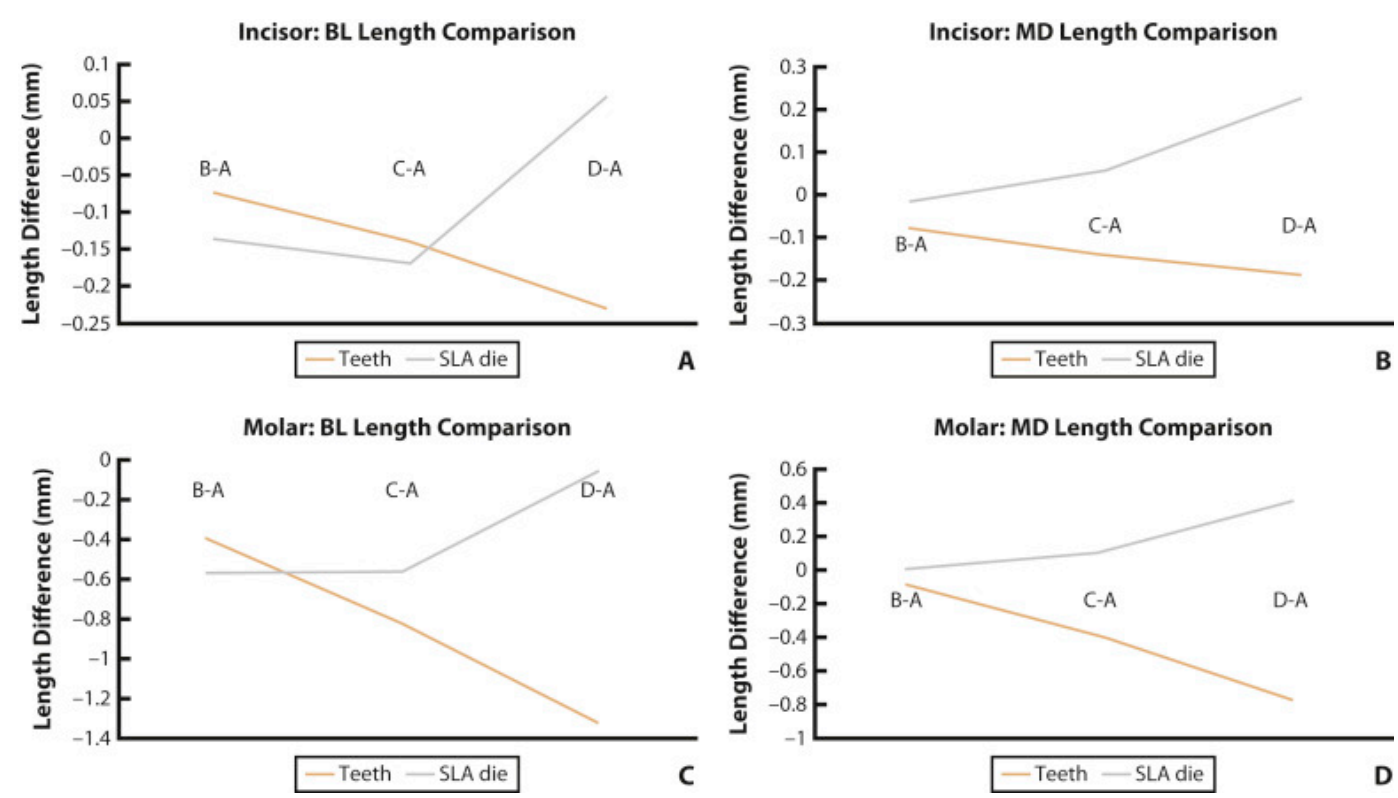

Figure 6. Length change between zones. A, Incisors buccolingual (BL). B, Incisors mesiodistal. C, Molars buccolingual. D, Molars mesiodistal. B-A, magnitude of length difference between zones B and A; C-A, magnitude of length difference between zones $C$ and $A ; D-A$, magnitude of length difference between zones $D$ and A. SLA, stereolithography.

By comparison with the subgingival contour of natural teeth, SLA dies tended toward undertrimming, which may affect the emergence profile of a definitive restoration. Kraus et al 7 introduced a concept regarding the anatomic or biological contours of a tooth, demonstrating that an area 2 to $3 \mathrm{~mm}$ apical to the finish line determines the emergence profile of a definitive restoration. In other words, emergence profile plays a key role in the development of a lifelike definitive restoration and a patient's ability to maintain gingival health. For this reason, clinicians and technicians should attempt to capture and replicate the subgingival morphology of teeth below the finish line of the preparation. Segal et al ${ }^{8}$ and Velasquez ${ }^{9}$ placed importance on capturing and maintaining the $2-\mathrm{mm}$ marginal zone on a die and proposed different trimming techniques in order to maintain this critical area. They reasoned that an ideal emergence profile must be developed in order to produce restorations/crowns that would mimic the cervical third of the unprepared tooth.

The results of the volume and length measurements emphasize the fact that natural teeth are flatter in profile, whereas the corresponding SLA dies are more concave. Clinically, this may result in overcontoured restorations made from SLA dies. Furthermore, the furcation area should be taken into consideration for multirooted teeth. This is one reason why the BL volume of the SLA dies were larger 
than the volume of the prepared tooth, as the SLA dies did not consider the furcation area (Fig. 1B). This loss of information could affect the contour of the definitive restoration and may affect periodontal health in the furcation areas. $\frac{12}{}$ When a crown is fabricated on a tooth with the margin extending apically into the furcation area, the vertical concavity and flutes should be taken into consideration for periodontal health and maintenance. $\underline{13}, \underline{14}$

The present study has several limitations with respect to methods, material, and technology used. Future research should include a third group of dies made by conventional methods, as no comparison was made between conventional technology and natural teeth or conventional technology and digital technology. Definitive crowns could be fabricated on these dies to assess the emergence profile and evaluate the relationship between trimming a die and the contour of a restoration. The current results may not be applicable to other CAD-CAM technologies. Since the results were based on 1 model of an intraoral scanner, further studies will be needed to investigate the morphology of dies made using comparative technologies.

\section{Conclusions}

Within the limitations of this in vitro study, the following conclusions were drawn:

1. For the comparison of angles, SLA dies did not replicate the subgingival contour of natural teeth on the BL surfaces of the incisal groups.

2. For the comparisons of length and volume, SLA dies were more concave and did not replicate the subgingival contour of natural teeth in the incisal and molar groups. In addition, SLA dies did not account for the furcal anatomy of natural molar teeth.

\section{References}

1 M.A. Mansueto, R.D. Phoenix A comprehensive approach to die trimming, J Prosthodont, 3 (1994), pp. 251-255

2 D.C. Chan, A.K. Chung, J. Haines, E.H. Yau, C.C. Kuo The accuracy of optical scanning: influence of convergence and die preparation, Oper Dent, 36 (2011), pp. 486-491

3 R.A. Tanquist Die trimming: a guide to physiologic contour, J Prosthet Dent, 48 (1982), pp. 485-489

4 D.B. Beck Precision technique for trimming dies using a magnification device, J Prosthet Dent, 43 (1980), pp. 590-591

5 B.M. Croll Emergence profiles in natural tooth contour. Part I: Photographic observations, J Prosthet Dent, 62 (1989), pp. 4-10

6 B.M. Croll Emergence profiles in natural tooth contour. Part II: Clinical considerations, J Prosthet Dent, 63 (1990), pp. 374-379

7 A.A. Dahlberg Physical anthropology: dental anatomy and occlusion: a study of masticatory system, Am Anthrolpol, 73 (1971), pp. 941-942

8 A.G. Segal, M.J. Gibbons, L. Zaslow An alternative to trimming dies, J Prosthet Dent, 52 (1984), pp. 138-139 
9 D. Velasquez Protecting the finish of stone dies during trimming, J Prosthet Dent, 68 (1992), pp. 557558

10 L.M. Jameson, W.F. Malone Crown contours and gingival response, J Prosthet Dent, 47 (1982), pp. 620-624

11 M.L. Perel Axial crown contours, J Prosthet Dent, 25 (1971), pp. 642-649

12 I.E. AppletonRestoration of root-resected teeth, J Prosthet Dent, 44 (1980), pp. 150-153

13 M.E. Gtier, R.W. Dunlap Linear variation of the root surface area of the maxillary first molar, J Periodontol, 56 (1985), pp. 39-43

14 R.A. Yuodelis, J.D. Weaver, S. Sapkos Facial and lingual contours of artificial complete crown restorations and their effect on the periodontium, J Prosthet Dent, 29 (1973), pp. 61-66

15 C.F. Parkinson Excessive crown contours facilitate endemic plaque niches, J Prosthet Dent, 35 (1976), pp. 424-429

16 J.F. Guth, C. Keul, M. Stimmelmayr, F. Beuer, D. Edelhoff Accuracy of digital models obtained by direct and indirect date capturing, Clin Oral Investig, 17 (2013), pp. 1201-1208

17 R.G. Nedelcu, A.S. Persson Scanning accuracy and precision in 4 intraoral scanners: an in vitro comparison based on 3-dimensional analysis, J Prosthet Dent, 112 (2014), pp. 1461-1471

18 S.H. Cho, O. Schaefer, G.A. Thompson, A. Guentsch Comparison of accuracy and reproducibility of casts made by digital and conventional methods, J Prosthet Dent, 113 (2015), pp. 310-315

19 S.B. Patzelt, S. Bishti, S. Stampf, W. Att Accuracy of computer-aided design/computer-aided manufacturing-generated dental casts based on intraoral scanner data, J Am Dent Assoc, 145 (2014), pp. 1133-1140

20 L.F. Andrews The six keys to normal occlusion, Am J Orthod, 62 (1972), pp. 296-309 